\title{
PISANDO CHARCOS. LA PINTURA SIN SOPORTE EN EL ARTE CONTEMPORÁNEO
}

\author{
Almudena Fernández Fariña \\ Universidade de Vigo
}

Data recepción: 2017/06/28

Data aceptación: 2019/07/16

Contacto autora: almudena@uvigo.es

ORCID: https://orcid.org/0000-0003-0089-3999

\section{RESUMEN}

El presente artículo analiza la práctica pictórica contemporánea que convierte la pintura derramada en absoluta protagonista de la obra. En un recorrido por la historia del arte se revisan las convenciones de la representación que trataron de ocultar la materialidad de la pintura, los artistas que la mostraron sin disimulo y los que, finalmente, la presentan explícitamente, sin artificios ni soportes intermediarios. Se identifican los posibles antecedentes de esta práctica, situando a la artista norteamericana Lynda Benglis como referente ineludible. El artículo pretende demostrar que el medio tradicional de la pintura no sólo sobrevive en la era digital, sino que reivindica su espacio en el arte contemporáneo presentándose en su estado más elemental.

Palabras clave: pintura, soporte, materialidad, goteo, vertido

\section{ABSTRACT}

This article analyses the contemporary pictorial practice of making spilled paint the sole protagonist of the work. In taking a journey through art history, it reviews conventions of representation that have sought to conceal the materiality of painting, the artists who openly depicted it, and those who, ultimately, presented it explicitly, without artifice or intermediary supports. Similarly, the possible history of this practice is traced, with the American artist Lynda Benglis being identified as an essential point of reference. The article also aims to demonstrate that the traditional medium of painting not only survives in the digital age, but also claims a space for itself in contemporary art by presenting itself in its most elementary state.

Keywords: painting, support, materiality, dripping, pouring

\section{Introducción}

En los últimos años venimos observando una corriente en la práctica pictórica que otorga todo el protagonismo al substrato material², a su plasticidad y maleabilidad. Se trata de artistas que renuncian a la representación, al gesto o la expresión, que abandonan el pincel y el proceso manual que le acompaña, artistas que prescinden del soporte que tradicionalmente acoge la pintura presentándola en el espacio expositivo sin intermediarios (fuera del cuadro). La pintura se libera de todo artificio y muestra su realidad como materia, su estado más elemental, radicalizando la pureza del medio defendida por el esencialismo del pensamiento moderno3. Hablamos de artistas que recuperan el dripping de Pollock o el 
soak-stein de Helen Frankenthaler, que gotean y chorrean la pintura desde el bote pero que, sin embargo, se distancian de las técnicas rompedoras de estos pintores modernos al renunciar a cualquier soporte mediador. El color se derrama directamente en el suelo y son la gravedad, la fluidez o la viscosidad propia del material, los elementos encargados de dar forma a la pieza. Los vertidos de pintura presentan formas aleatorias y defienden la posibilidad de una existencia liberada definitivamente del cuadro. Este artículo sitúa las Fallen Painting (1968) de Lynda Benglis como antecedente directo de esta práctica, evidenciando su prolongación en el arte contemporáneo en las obras de Peter Zimmermann, Rainer Splitt, Miguel Ángel Molina, Jorge Magyaroff o Kristof Kintera.

\section{Con Manet empezó todo}

Hasta el siglo XX la historia de la pintura occidental se escribió aceptando que ciertas reglas eran inherentes a su categoría. Mientras que una de aquellas reglas respondía a una función mimética ${ }^{4}$, esto es, a una concepción de la pintura como un espejo que refleja la realidad ${ }^{5}$, la otra regla aludía al ilusionismo espacial, al cuadro concebido -desde el Renacimiento ${ }^{6}$ - como una ventana abierta al mundo.

La pintura como espejo o como ventana constituía el paradigma de la correcta representación, convención poderosa que, durante siglos, impidió a la pintura revelar su verdadera naturaleza material. Los grandes maestros demostraban su destreza negando la materia, extendiéndola con el pincel, fundiendo el color, cubriendo y puliendo la superficie del lienzo u ocultando sus propias huellas para que las imágenes ganaran fidelidad y fueran apariencias del mundo visible? ${ }^{7}$. Mostrar la textura de la pintura o visibilizar la pincelada ponía en evidencia el proceso manual y la realidad material de la pintura, considerándose ruidos ópticos que dañaban la legibilidad de la imagen y rompían el hechizo ilusionista. Eran, en definitiva, factores negativos impropios de la habilidad de un gran maestro ${ }^{8}$. Como asevera Cabo Villaverde: "La textura repugnaba por su sensualidad, su subjetividad, su tendencia a destruir la pureza formal del acabado. El cuadro debía aparecer como un resultado que no delatase traza alguna del proceso de su ejecución". ${ }^{9}$

Durante siglos la pintura asumió todo un repertorio de convenciones técnicas para generar ilusión óptica, lo cual implicaba tanto disimular la materia como ocultar el soporte sobre el que ésta se aplica, tal y como afirma Foucault: "desde el quattrocento, en la pintura occidental era tradición intentar velar y eludir el hecho de que la pintura estaba insertada, o encuadrada, en un fragmento de espacio determinado que podía ser un muro -en caso del fresco-, una tabla de madera, o incluso una tela o un pedazo de papel"..$^{10}$ Desde el Renacimiento, el espectador se había habituado al soporte "silencioso"11, al artificio de la representación que niega el cuadro y borra el rastro de la materia pictórica.

El cambio en las formas de representación comienza a visibilizarse en la pintura del Romanticismo, en la factura liberada de las encorsetadas formas académicas, dando paso a pinceladas vigorosas que canalizan la subjetividad y el sentimiento. Es con Manet (Francia, 1832-1883) cuando se produce una quiebra profunda, una ruptura que continuarán los impresionistas y que, a día de hoy, pervive en el arte contemporáneo. Manet trasciende la imitación del modelo y comienza a privilegiar los valores formales sobre el contenido, fija la atención sobre el plano pictórico dejando al descubierto lo que, hasta entonces, la materia pictórica había tratado de encubrir: la planitud, la trama del lienzo, la forma del soporte, la variable densidad de la pintura o la huella del pincel.

Manet muestra explícitamente las cuestiones intrínsecas de la pintura, reconociendo abiertamente sus propios límites y proclamando la superficie y la materia con que fueron pintadas. Es por ello que Greenberg entiende a Manet como primer pintor moderno:

Los cuadros de Manet son las primeras pinturas modernas a causa de la franqueza con que confiesan la superficie plana en que fueron pintados. Los impresionistas en la estela de Manet, renunciaron a las preparaciones previas de la tela y a los barnices para que resultara visualmente claro que los colores utilizados estaban hechos con pintura procedente de tubos $y$ potes. ${ }^{12}$ 
A partir de Manet la imagen pictórica cambia de naturaleza, su concepción plástica da un salto equiparable al que supuso la invención de la perspectiva en el Renacimiento. Los pintores se desentendieron gradualmente de la representación, centrando sus intereses en otras cuestiones como la estructura de la obra, las cualidades formales, la expresión o el tratamiento de la materia en la superficie. Como manifiesta expresamente Michael Fried "[...] la historia de la pintura desde Manet, pasando por el Cubismo Sintético y Henri Matisse, se puede caracterizar en términos del abandono gradual, por parte de la pintura, de la tarea de representar la realidad -o del poder real de la pintura para representarla- a favor de una preocupación creciente por los problemas intrínsecos a la propia pintura". 13

\section{La materia pictórica como tema}

La pintura impresionista es un ejemplo de cómo -en la medida que la tarea de representar la realidad queda relegada por otros intereses como la luz, el movimiento o la mezcla óptica del color-, la pintura emerge y revela su condición material. Pensemos en los empastes de espátula de Cezanne (Francia, 1839-1906), en las pinceladas cargadas de materia de los cuadros de Van Gogh (Países Bajos, 1853-1890) o en los impetuosos toques de pincel de las Ninfeas de Monet (1840-1926). Aunque en estos casos la materia pictórica todavía aparece subordinada a la representación, las pinceladas comienzan a evidenciar su corporeidad y maleabilidad. Las imágenes pintadas por los impresionistas no ocultan que han sido constituidas por la superposición de capas físicas de una sustancia con color que sale de un bote o tubo.

El alarde matérico continuará en sucesivos movimientos de vanguardia como el fauvismo o el expresionismo alemán; sin embargo, habrá que esperar a la inmediata posguerra para que los pintores del expresionismo abstracto se liberen definitivamente de la representación, del referente o del significado para hacer explícitas las cualidades inherentes a la materia pictórica, es decir, la fluidez, el espesor o la densidad y su comportamiento en la superficie del lienzo: empastes, manchas acuosas, chorretones, goteos, salpicaduras, etc.
En este momento las teorías del crítico americano Clement Greenberg se imponen como un dogma. Para Greenberg el objetivo de la pintura era alcanzar la pureza, encontrar la verdadera esencia y desechar cualquier referente externo, cualquier ilusión de espacio, rigiéndose exclusivamente por las normas del propio medio' ${ }^{14}$ :

Desde Giotto a Courbet, la primera tarea del pintor había sido excavar una ilusión de espacio tridimensional en una superficie plana. El observador miraba a través de esa superficie como a través del proscenio de un escenario. El modernismo ha disminuido la profundidad de ese escenario más y más hasta que hoy el telón de fondo ha llegado a coincidir con el de delante, y éste es el único sobre el que hoy puede trabajar el pintor. ${ }^{15}$

Según esta afirmación, para Greenberg la ilusión de profundidad de la ventana albertiniana debía empujar las formas representadas para hacerlas coincidir literalmente con el plano del cuadro. Roto el hechizo de la ilusión, el cuadro ya no podrá ocultar su condición de objeto real, tampoco la planitud de su superficie ni la sustancia viscosa aplicada sobre ella.

La pintura convertida en una entidad autónoma, autorreferencial, autorreflexiva y autosuficiente se repliega en su propio lenguaje y muestra, sin disimulo, sus propiedades físicas ${ }^{16}$. El comportamiento de la materia confirma definitivamente su presencia en los cuadros de pintores como Jackson Pollock (Estados Unidos, 1912-1956) o Helen Frankenthaler (Estados Unidos, 1928-2011).

En los años cuarenta Pollock deja de pintar en vertical para abordar, por primera vez, el dripping [goteo]. El artista libera la tela de la tensión del bastidor, la extiende en el suelo y se mueve alrededor de ella chorreando y goteando pintura líquida con pinceles, con palos o directamente desde el bote (fig. 1). Los movimientos impulsivos de la mano ceden el control a las imposiciones de la gravedad y el azar. La técnica de Pollock obligaba a cambiar la relación física entre el cuerpo y el cuadro, la tela extendida en el suelo exigía una implicación del cuerpo que nada tenía que ver con el posicionamiento estático del pintor, erguido y paralelo al caballete. Este modo de abordar el proceso pictórico fue denominado 


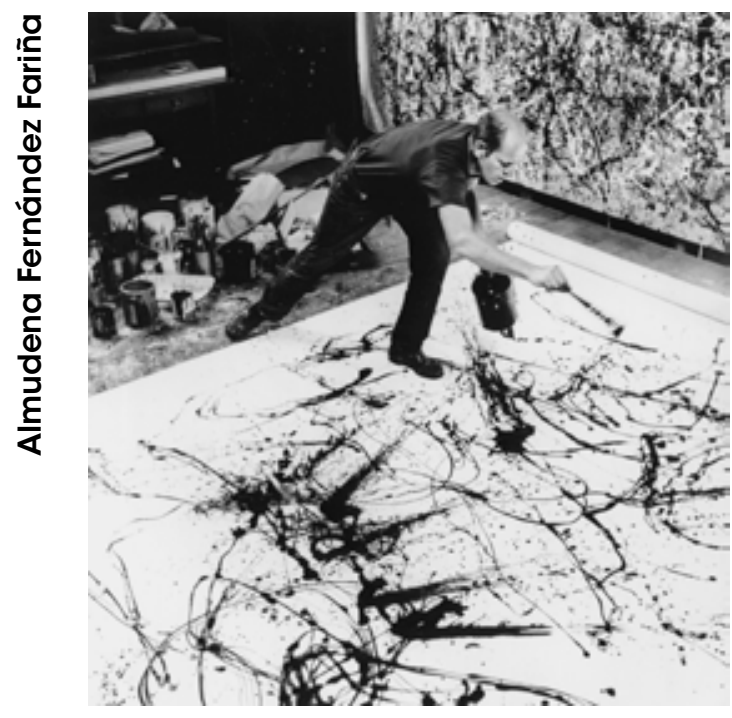

Fig. 1. Namuth, Hans, fotografía de Jackson Pollock pintando en su estudio, 1951

por el crítico americano Harold Rosenberg como action painting ${ }^{17}$.

Por su parte, Helen Frankenthaler, a principio de los años cincuenta, empieza a utilizar el soak-stain [mancha empapada]. La artista aplica la pintura muy diluida sobre un lienzo sin preparación, el color se esparce y forma manchas transparentes que impregnan la tela cruda, los contornos quedan difuminados, definidos por el propio proceso de absorción y secado de la pintura (fig.2).

Para conseguir este efecto Frankenthaler trabajaba, al igual que Pollock, en horizontal, extendiendo el lienzo en el suelo y vertiendo el óleo, muy diluido en trementina, desde diferentes puntos. Las fotografías realizadas a ambos artistas pintando evidencian las diferencias al abordar el proceso pictórico: Pollock salpica y derrama la pintura con gestos amplios y vehementes; Frankenthaler agachada o arrodillada junto al lienzo, vuelca los botes cuidadosamente ${ }^{18}$. La técnica del soak-stein proporcionaba un resultado traslúcido que unificaba color y soporte, permitiendo prescindir del pincel, implicaba al azar en el proceso y, sobre todo, explicitaba la fluidez de la pintura.

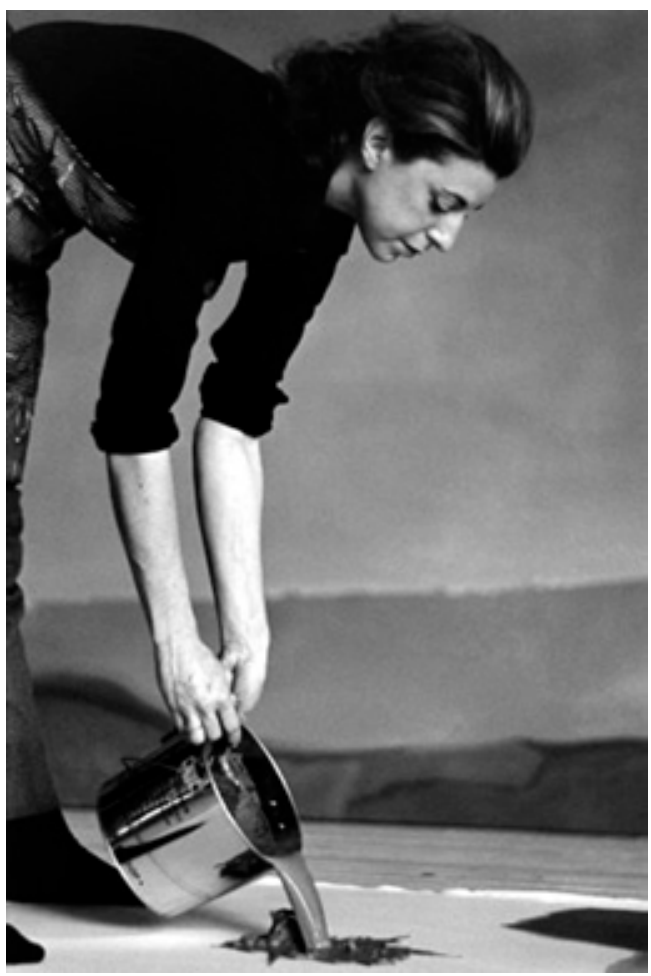

Fig. 2. Haas, Ernst, fotografía de Helen Frankenthaler pintando en su estudio, 1969

Pollock y Frankenthaler son claros exponentes de una pintura liberada del virtuosismo y las tareas representativas; ambos convierten el comportamiento de la materia pictórica en el tema de sus cuadros. No obstante, sus rompedoras propuestas mantienen la convención de presentar la pintura en el dispositivo que tradicionalmente acoge la representación, esto es, el cuadro, ese objeto cultural que convierte en ficción todo lo que contiene en su superficie.

\section{La materia sin soporte}

En 1968 Lynda Benglis (Estados Unidos, 1941) expone, por primera vez, Fallen Paintings [Pinturas caídas]. La artista presenta la masa pictórica sin soporte intermediario, nada se interpone entre la viscosidad del material y la realidad. Benglis derrama directamente en el suelo una mezcla de pigmentos y látex ${ }^{19}$, siendo la gravedad y la densidad de la materia lo que da forma a la pieza. El vertido era una forma de liberar la materia del 


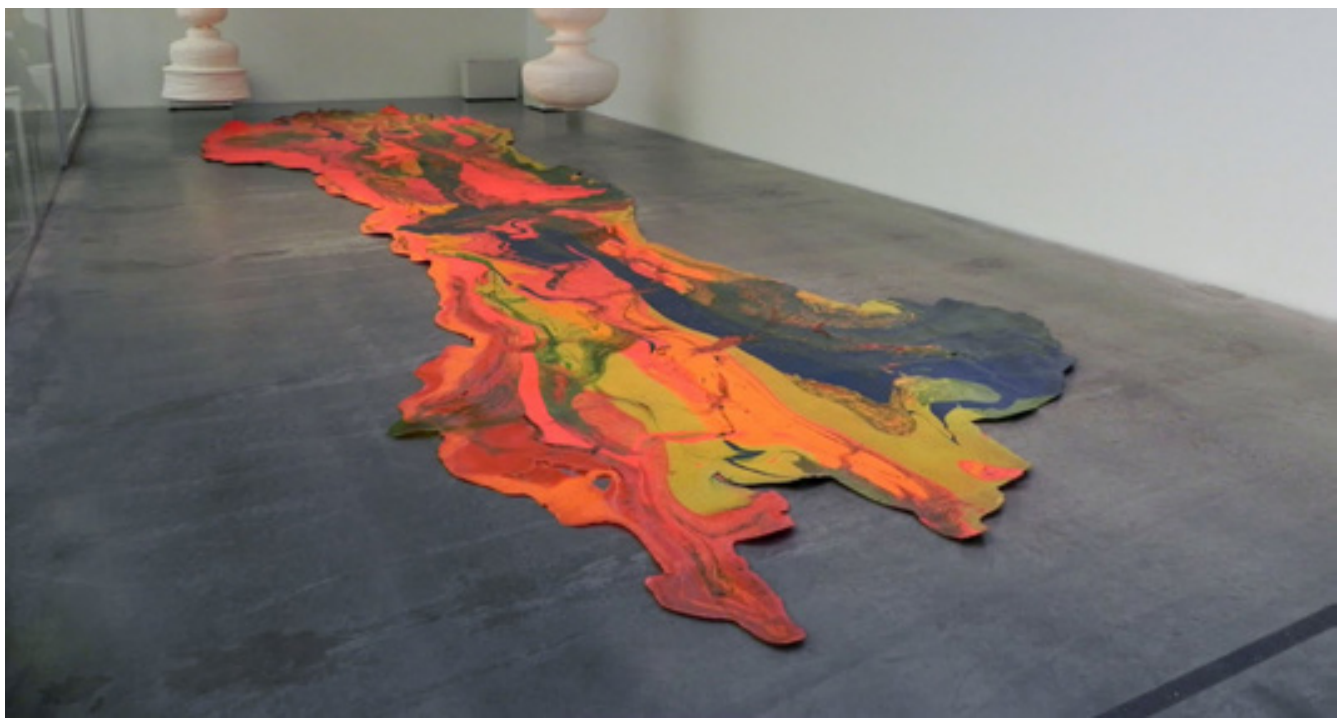

Fig. 3. Benglis, Lynda, Contraband, 1969. Colección Whitney Museum of American Art, Nueva York

constreñido y rectilíneo formato convencional de la pintura, y de integrar, con un solo gesto, materia, proceso, color e imagen.

Las Fallen Paintings recuperan el gesto del soak-stein de Frankenthaler y, al mismo tiempo, registran el movimiento del cuerpo y la energía del dripping de Pollock. Aunque la influencia de ambos pintores es manifiesta, Benglis ${ }^{20}$ radicaliza sus propuestas prescindiendo del lienzo. Con estas pinturas informes, la artista, vinculada al movimiento feminista, hacía una lectura en clave de género, parodiando el gesto heroico de los expresionistas abstractos y cuestionando las alabanzas de la crítica formalista hacia este movimiento. Pero, además, la organicidad de sus formas y vivacidad de sus colores desafiaban la estética del minimalismo: la sobriedad geométrica, la pulcritud de los acabados, la rigidez de los materiales industriales y la dominante presencia masculina de los artistas adscritos a este movimiento.

Las Fallen Paintings se presentan liberadas del soporte, la masa pictórica ha abandonado el cuadro, el espacio de la representación, y se extiende espesa por el suelo. Pero estos vertidos no sólo exhiben orgullosos su materialidad, sino que niegan la bidimensionalidad de la pintura, la convención de la mirada frontal-paralela y la verticalidad del muro. La pintura sin soporte irrumpe en el espacio apropiándose del lugar asignado tradicionalmente a la escultura.

En 1969 Benglis fue seleccionada para participar en la célebre exposición Anti-lllusion: Procedures/Materials, en el Museo Whitney de Nueva York. Sin embargo, en el último momento, la "pintura caída" titulada Contraband (1969) (fig.3) que Benglis había realizado específicamente para la muestra, fue retirada del espacio que se le había asignado en la galería principal, dado que los comisarios no veían cómo encajarla en la exposición. Contraband fue desplazada al atrio del museo y colocada sobre una rampa, cambiando la orientación horizontal con la que Benglis la había concebido²1. Para Benglis, nadie entendió que su pintura pudiera estar ubicada en el suelo, además Richard Serra y Robert Ryman, participantes en la muestra, se negaron a que la colorida pieza se expusiera cerca de sus obras ${ }^{22}$. Resulta paradójico que, a pesar de las radicales rupturas planteadas por los artistas a final de los sesenta, la supresión del límite entre pintura y escultura fuera tan difícil de asimilar.

Las Fallen Paintings de Benglis congelan la acción de un gran vertido de pintura. En estas piezas los colores -generalmente rojo, amarillo, naranja, azul y verde- se fusionan aleatoriamente creando, al solidificarse, sugerentes formas que 


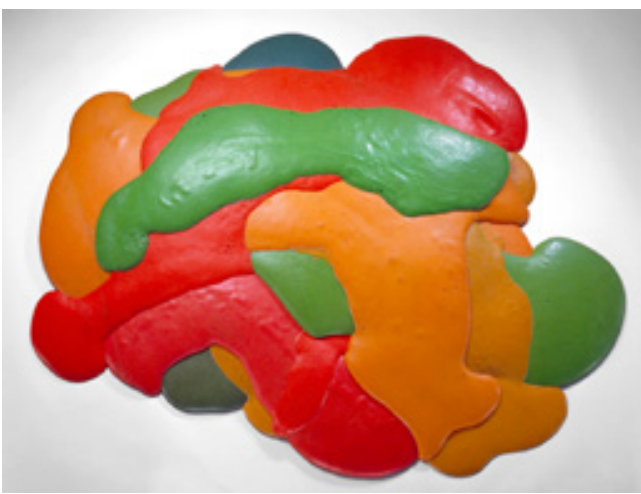

Fig. 4. Benglis, Lynda, Night Sherbet A, 1968

semejan lenguas de color con efecto marmoleado. En otras piezas como Night Sherbet A (1968) (fig.4) o Untitled (VW) (1970), Benglis superpone varios vertidos sin dejar que los colores se mezclen. Esta forma de proceder quedó documentada en el reportaje "Fling, Dribble and Dip" que la revista Life le dedica el 27 de febrero de 1970²3. En la secuencia fotográfica aparece la artista sujetando grandes latas de pintura y esparciendo el color por el suelo, una coreografía que conjugaba precisión y azar, y ponía el acento en lo performático del proceso (fig. 5).

En el artículo se incluía una pequeña fotografía de Pollock ${ }^{24}$ pintando junto con una declaración en la que se calificaba a Benglis como su heredera ${ }^{25}$. Efectivamente, podríamos considerar a Benglis sucesora de Pollock en cuanto a la radicalidad de su propuesta, pero no en cuanto al reconocimiento y recepción pública que disfrutaría su predecesor. Basta con revisar el título del artículo que Life dedica a Pollock en agosto de 1949, titulado: "Is he the greatest living painter in the United States?" [¿El pintor vivo más grande de Estados Unidos?], para apreciar hasta qué punto la cultura de posguerra norteamericana se rendía ante la energía y originalidad de aquel joven artista. Todo lo contrario a lo que sucedía con el trabajo de Benglis, durante mucho tiempo ignorado por la comunidad artística.

En 1974, en un gesto de protesta por las dificultades que encontraba para visibilizar su trabajo, la artista publicó en la revista Artforum una controvertida imagen para anunciar su exposición en la galería Paula Cooper ${ }^{26}$. Se trataba de una

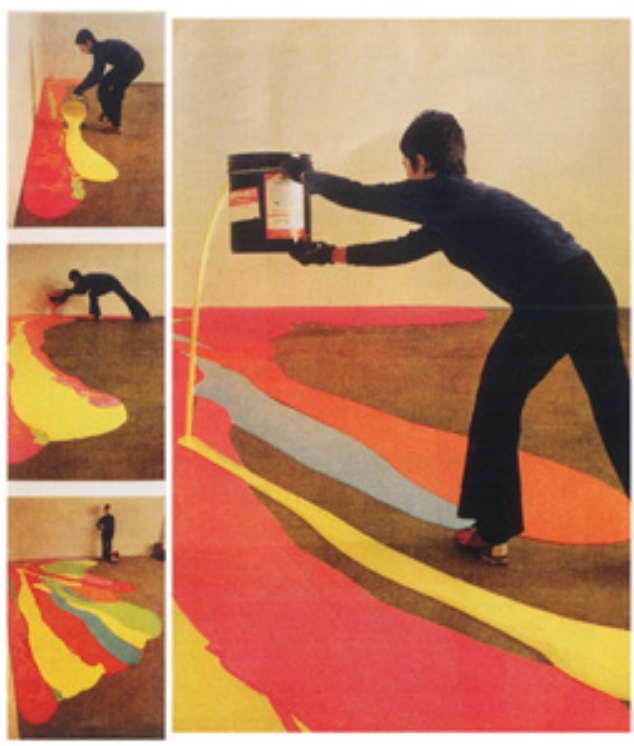

Fig. 5. Groskinsky, Henry, secuencia fotográfica de Lynda Benglis pintando, 1970. Publicada en revista Life, 27 de febrero, 1970

fotografía en la que la propia Benglis posaba desnuda sujetando un enorme falo. Con un gesto desafiante, gafas de sol y el cuerpo embadurnado de aceite, la artista se mofaba del sistema del arte y de los atributos necesarios para alcanzar cierto reconocimiento. La parodia de la masculinidad, latente en las Fallen Painting, se mostraba de forma explícita en un gran pene postizo. La polémica que desató el anuncio hizo famosa a Lynda Benglis, convirtiéndola en un hito de la historia del feminismo. Sin embargo, la enorme contribución de sus pinturas de suelo tendría que esperar décadas para obtener el merecido reconocimiento.

De forma simultánea, en Europa, el artista César Baldaccini (Francia, 1921-1998), conocido por sus famosas Compresiones, realizadas con objetos y desperdicios industriales, empieza a trabajar en una nueva serie que denominará Expansiones, en realidad, vertidos a base de espuma de poliuretano. César derrama en el suelo la espuma coloreada controlando y jugando con los tiempos de solidificación. Para presentar las expansiones el artista experimenta diferentes variantes, bien mostrando la masa de color acompañada del recipiente desde el que se ha volcado (fig. 6), o bien 


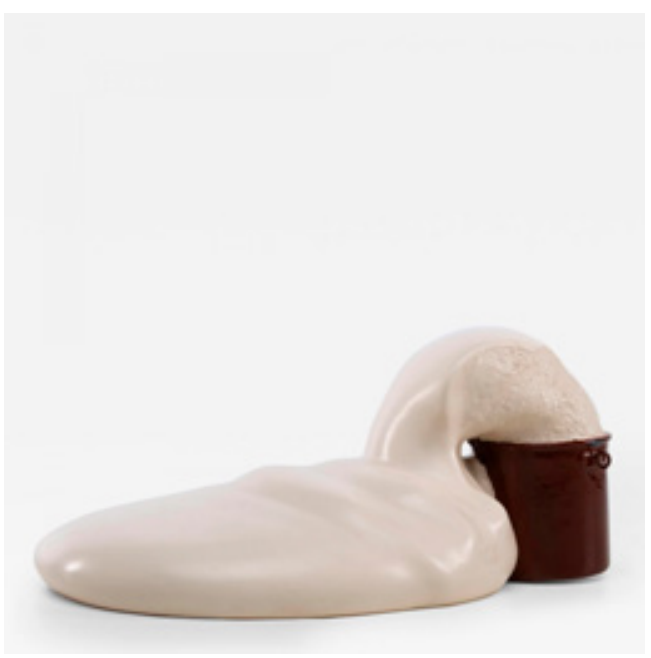

Fig. 6. Baldaccini, Cesar, Expansion-jaune, 1967

vertiendo directamente la espuma en presencia de público y transformando las Expansiones en concurridas performances. Aunque la trayectoria de este artista se desenvuelva preferentemente en el campo de la escultura, parece inevitable observar en sus Expansiones un gesto pictórico comparable al dripping de Pollock o el soak-stein de Frankenthaler.

\section{Charcos de pintura, pintura contemporánea}

Las Fallen Painting de Lynda Benglis son un claro antecedente de la práctica pictórica contemporánea que convierte la pintura derramada en única y absoluta protagonista de la obra. Resulta curioso que, en un tiempo en el que las nuevas tecnologías dominan la creación y la manipulación de imágenes, algunos artistas -en un proceso inverso a la desmaterialización digitalsientan el impulso de volcar botes de pintura para contemplar el vertido fluyendo en el suelo. Parece que un espeso y brillante charco de pintura puede ser igual o más fascinante que el espacio intangible, limpio y virtual generado por los nuevos medios.

La obra de Peter Zimmermann ${ }^{27}$ (Alemania, 1956), es fácilmente identificable por las formas fluidas de sus Blob Paintings [Pinturas de Gota]. Se trata de cuadros realizados con resina epoxi pigmentada que, a simple vista, recuerdan las

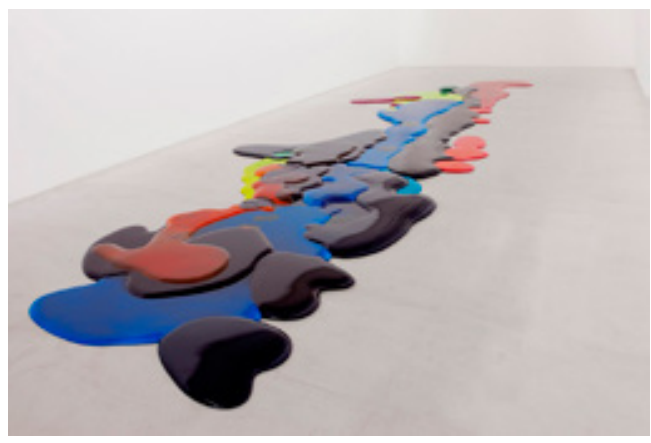

Fig. 7. Zimmermann, Peter, Leak. Intervención en Galerie Perrotin, Paris, 2010

composiciones del Color Field. Sin embargo, tras la apariencia de un lenguaje moderno, se esconden otros significados. El artista parte de imágenes tomadas de internet, del cine o de anuncios de revistas que digitaliza, manipula y distorsiona mediante algoritmos gráficos. El resultado son manchas abstractas donde la imagen fuente es completamente irreconocible. Las manchas abstractas son transferidas al lienzo como vertidos de resina epoxi líquida.

Al igual que Frankentaler, Zimmermann vuelca el color cuidadosamente, superponiendo capas translúcidas de colores brillantes. Aunque el proceso es lento y controlado, el resultado nunca es predecible. La resina epoxi aporta una nueva dimensión a las imágenes, el material solidificado sobre el lienzo blanco les confiere la apariencia de una luz que emana del interior de las formas, acentuando la profundidad e intensificando los colores.

En 2009, las Blob Paintings abandonan el soporte del lienzo para derramarse directamente en el espacio real. Primero será una pieza sin título en la galería berlinesa Michael Janssen (2009), a la que seguirá, un año después, la intervención denominada Leak (fig. 7), en la Galería Perrotin de París. En ambas intervenciones, y como en las Fallen Paintings, las manchas de resina se esparcen en el suelo. Sin embargo, las piezas de Zimmermann no surgen de la acción de un único vertido donde el color se mezcla aleatoriamente, sino de varios derramamientos superpuestos en distintos tiempos y en capas de color perfectamente diferenciadas. El resultado es similar a la obra Night Sherbet A de Lynda Benglis. Los 


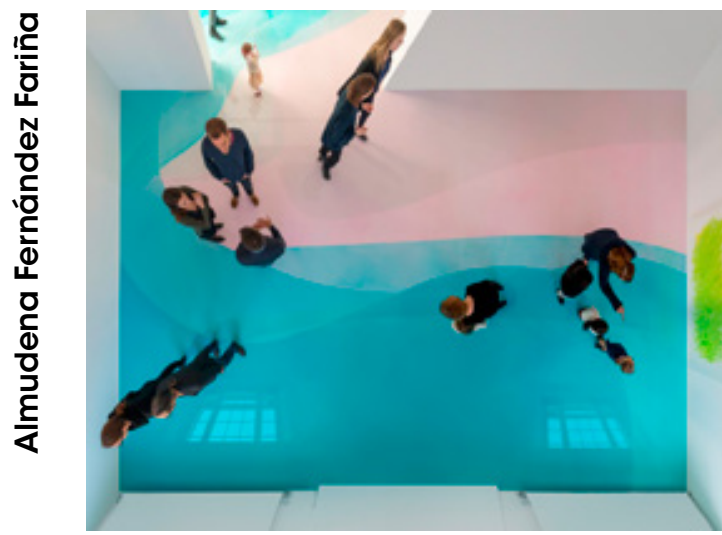

Fig. 8. Zimmermann, Peter, Schule von Freiburg. Intervención en Museo de Arte Contemporáneo de Friburgo, 2016

charcos de pintura de Zimmermann remiten a una acción repetida, a vertidos controlados y a gestos menos impetuosos. Como complemento de Leak, Zimmermann realiza -igualmente en la Galería Perrotin- Gravity, una intervención en la que la pintura no se sitúa en el suelo, sino que se dispone por el techo al modo de coloridas y goteantes manchas de humedad.

En 2016, Zimmermann presenta Schule von Freiburg (fig.8), en el Museo de Arte Contemporáneo de Friburgo. En esta intervención el artista vierte resina en el suelo hasta inundar completamente toda el área del museo: 400 metros cuadrados cubiertos con una capa de resina brillante que da al pavimento el aspecto de una superficie de hielo o vidrio coloreado. Los colores van cambiando en el recorrido por las diferentes salas, transformando el suelo del museo en un gran lienzo sobre el que pueden caminar los visitantes.

A principios de los años noventa, Rainer Splitt28 (Alemania, 1963), comienza su serie Pourings [Vertidos] (fig. 9). Vertidos de pintura y emulsiones sintéticas que invaden el suelo del espacio expositivo o se esparcen sobre distintos objetos y superficies. La gravedad y densidad del fluido parecen determinar la arbitrariedad de las formas, sin embargo, cada vertido es el resultado de un calculado proceso en el que el artista estudia previamente las cualidades y comportamiento de la materia: la distancia del bote al suelo, la inclinación del recipiente, el impulso en el volcado, la dirección de la expansión, la porosidad de la

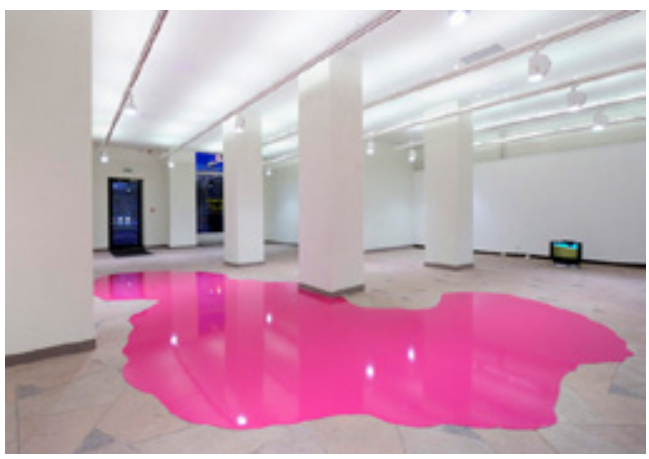

Fig. 9. Splitt, Rainer, Farbguss Vilnius. Intervención en GoetheInstitut, Vilnius, 2009

superficie, los contornos que dibuja el esparcimiento o el tiempo gradual de secado. Un estudio exhaustivo para generar un vertido de apariencia casual y azarosa.

Los charcos de pintura de Splitt se caracterizan por la monocromía, la dimensión, la luminosidad del color y un aparente estado líquido. La mancha de color entabla un diálogo de opuestos con los elementos sobre los que es derramada: el brillo e intensidad del color frente a la neutralidad de los espacios; la forma orgánica, irregular e inconsistente frente a las estructuras rectas, geométricas y sólidas de la arquitectura. El vertido, completamente solidificado, se extiende en el suelo y parece seguir avanzando para interrogarnos sobre la relación con el espacio, el tiempo y la materialidad de la pintura.

La fluidez de la materia pictórica es la protagonista de otras series de Splitt como sucede en el caso de Paperpools [Papeles-piscina], que comienza en 2008. El artista pliega papeles en forma de caja que sirven de contenedores, después los llena de pintura líquida, la materia se adapta a la forma del espacio y, posteriormente, los vacía. Los Paperpoo/ se exponen desplegados mostrando una huella precisa, un contorno que señala el lado por el que la pintura ha evacuado el improvisado recipiente.

La necesidad de presentar la pintura como una sustancia que fluye, se expande y ocupa un lugar en el espacio, es patente en la obra de Miguel Ángel Molina'29 (España, 1963). A final de los años noventa, el artista descubre que, en los charcos de pintura del estudio o en las gotas de colores 


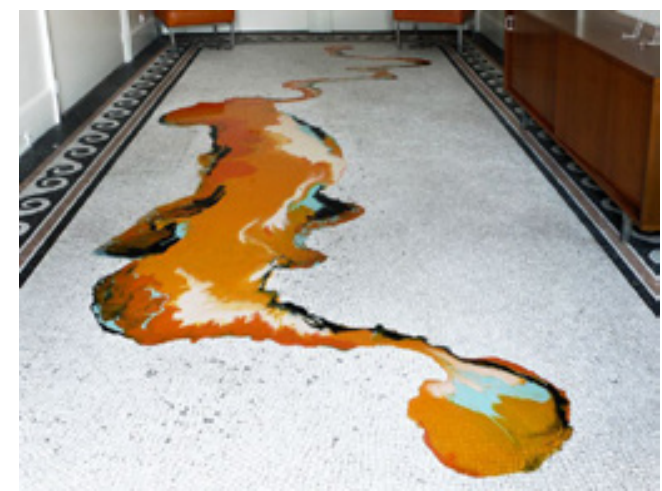

Fig. 10. Molina, Miguel Ángel, Peinture en forme de flaque de peinture. Intervención en Commande de la Ville de Nanterre, 2006

salpicadas en sus zapatos, la pintura adquiría una dimensión real. La materia pictórica muestra su entidad en L'espace à la intérior de ma main, una fotografía de 1997 en la que la mano del artista estruja una masa de pintura naranja que se desborda entre sus dedos. La imagen nos sitúa entre la atracción por el tacto untuoso y sensual de la materia, y la imposibilidad de contenerla. Para Miguel Ángel Molina, la pintura no es un vehículo para representar imágenes dirigidas al ojo -el artista cuestiona la convención de la experiencia perceptiva óptica-, sino una propuesta de diálogo físico entre el cuerpo y la materia, en definitiva, una experiencia perceptiva háptica: "La pintura ha sido históricamente el sujeto de los visible, pero en el día a día, mis relaciones con ella eran otras que la visibilidad. Poco a poco, la consciencia de una percepción táctil de la pintura comenzaba a dibujarse como el contrapeso necesario a lo óptico". ${ }^{30}$

La pintura de Miguel Ángel Molina se derrama sobre objetos como libros (Manuel de peinture, 2005); pomos de puerta (ICI, 2005); el cuerpo del propio artista creando una segunda piel (Peinture comme peau, 1997); o sobre el suelo de diferentes espacios. En Peinture en forme de dégât de peinture, intervención realizada en la Escuela de Bellas Artes de Rouen, (2003), el suelo del espacio expositivo se muestra completamente anegado por vertidos de diferentes colores.

La pintura derramada protagoniza la serie Peinture en forme de flaque de peinture [Pintura en forma de charco de pintura] (fig. 10) que

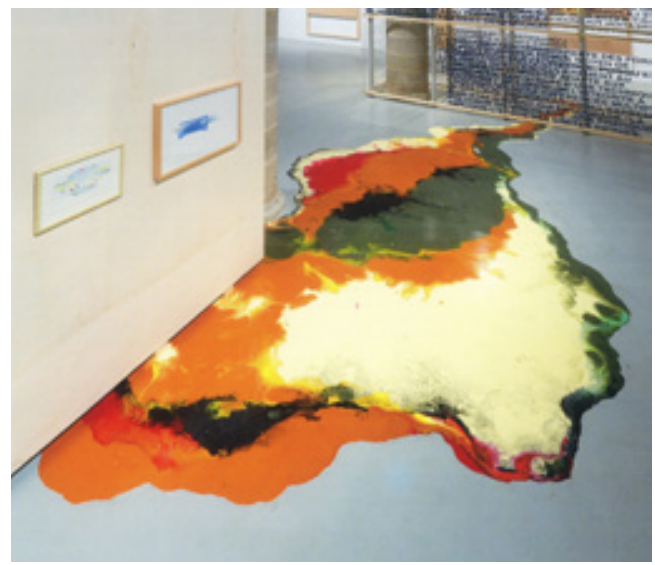

Fig. 11. Molina, Miguel Ángel, Peinture en forme de flaque de peinture. Intervención en Centre d'Art La Panera, exposición Afinidades electivas, Lleida, 2008

incluye diversas intervenciones: una gran mancha amarilla cae en cascada por las escaleras de la Casa de la Cultura de Amiens (exposición De singuliers débordements..., 2002); dos cuadros vacíos parecen haberse desangrado provocando un charco de colores a su alrededor (Centre d'Art 10NEUF de Montbelliard, 2005); un gran vertido de colores se cuela bajo un tabique y discurre entre las obras que integran la exposición Afinidades electivas (Centre d'Art La Panera, Lleida, 2005) (fig. 11); una pared en la galería parisina Christophe Gaillard se pinta de color naranja, desbordándose y deslizándose la pintura por el suelo (2005); los restos de un vertido rodean el espacio dejado por un cuadro ausente (Exposición Zone de turbulence, Paris 2006). La pintura, en su condición de materia líquida, insiste en desbordar aquellos espacios o superficies que traten de contenerla.

Ian Davenport ${ }^{31}$ (Reino Unido, 1966) huye de cualquier intento de narración o representación. El tema de sus pinturas es la pintura misma, es decir, la fisicidad y comportamiento de la materia. Las obras que se han convertido en su seña de identidad son los cuadros pintados con vibrantes colores y la técnica del goteo y el vertido: con una jeringa el artista gotea cuidadosamente el color sobre una superficie vertical y ligeramente inclinada en la parte inferior, de tal forma que la gravedad y la fluidez de la pintura dibujan líneas perfectas en su recorrido hasta descomponerse al 


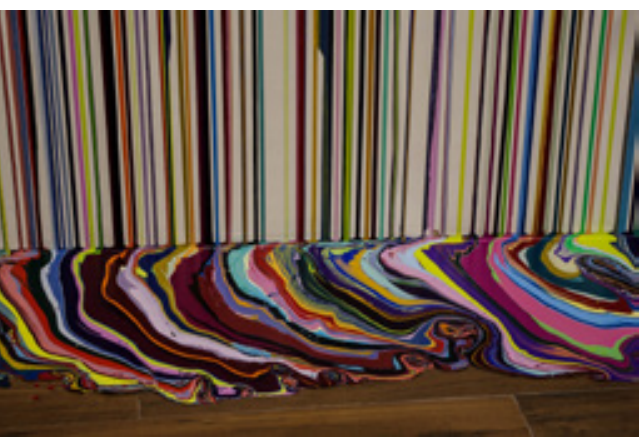

Fig. 12. Davenport, lan, Reflex. Intervención en Galleria Giacomo Guidi, Roma 2012

llegar a la parte inclinada. La pulcritud del goteo y vertido de Davenport, se aleja de la espontaneidad del dripping de Pollock y las Fallen Paintings de Benglis. En su caso la pintura se aplica de forma sistemática: el artista determina el espesor de la materia, calcula la cantidad de pintura introducida en cada jeringa y valora el deslizamiento sobre superficies de distinta porosidad, como madera, aluminio o lienzo. El resultado son composiciones y descomposiciones de líneas que varían en un juego inagotable de combinaciones y yuxtaposiciones cromáticas.

En sus intervenciones murales, como las realizadas en la Universidad de Warwick (2004), en la Galería Giacomo Guidi (Roma, 2012) (fig.12) o en Mision Gallery (Gloucester, 2015), Davenport utiliza la misma técnica de líneas trazadas por goteo: vacía la jeringa en la parte superior del muro y deja que el color se deslice hasta llegar al suelo, en este punto la pintura se derrama sin control provocando un charco de colores fundidos. El efecto es similar al que el artista consigue inclinando la parte inferior de sus cuadros, pero en este caso la pintura desborda el plano vertical y se extiende en el suelo.

En su serie Expansiones (2014) Jorge Magyaroff32 (Colombia, 1979), no sólo coincide con César Baldaccini en la elección del título, sino que sus vertidos de laca brillante se presentan acompañados del recipiente que los ha volcado. Se trata de una serie en la que los botes de pintura aparecen tumbados sobre unas repisas instaladas en la pared, la pintura desbordándose del contenedor y discurriendo por el muro, acaba su recorrido formando generosos charcos en el

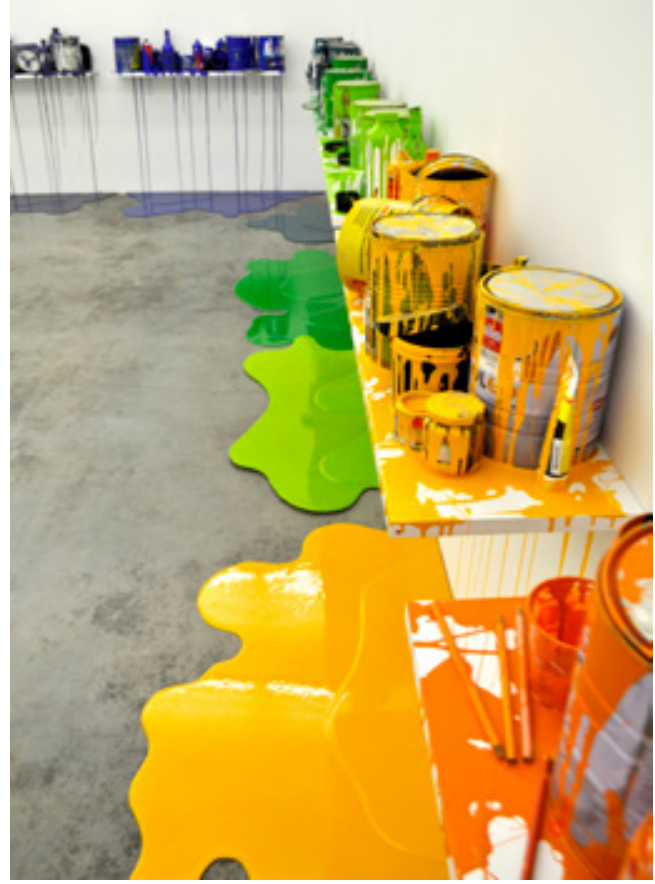

Fig. 13. Magyaroff, Jorge, Expansiones, 2014

suelo (fig. 13). Sin embargo, nada hace pensar que estos chorretones y vertidos sean fruto de un accidente o del azar. En su disposición perfectamente ordenada o en el degradado de color, se percibe el gesto consciente del artista, la voluntad de crear una armónica composición.

El lugar que ocupa la materia pictórica en la obra de Magyaroff se pone de manifiesto en el título No hay que llorar sobre la pintura derramada (2013), una serie en la que el artista construye auténticos bodegones donde la materia pictórica, en lugar de estar al servicio de la representación, se presenta convertida en objeto. Botes viejos y usados se disponen en el suelo o se acumulan en repisas distribuidas por el espacio, algunos botes volcados vierten la pintura de forma controlada, directamente en el suelo y sin salpicar la pared. Algo similar sucede en la serie La muerte de la pintura (2013), donde el artista presenta botes solitarios y agujereados que han derramado todo su contenido dejando un charco alrededor (fig. 14).

En el proyecto Incisiones (2012), la materia pictórica adquiere otro significado. En esta in- 


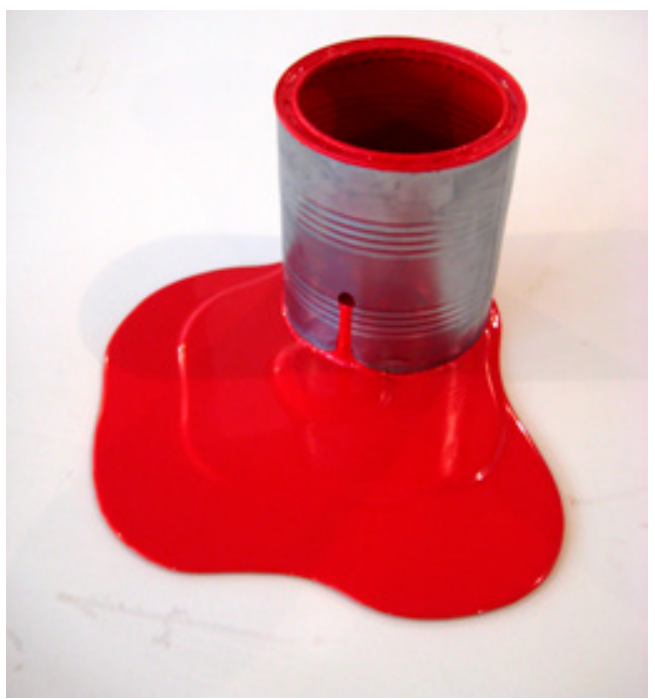

Fig. 14. Magyaroff, Jorge, serie La muerte de la pintura, 2013

tervención Magyaroff realiza varias perforaciones en el muro de un espacio, simulando que de esos agujeros hubiera manado gran cantidad de pintura roja. Con la elección del color, el artista nos sugiere un espacio herido y, con los charcos multiplicados por el suelo, una arquitectura que parece haberse desangrando.

En la misma lectura que Incisiones se encontraría la obra Red is coming (2007), de Kristof Kintera ${ }^{33}$ (República Checa, 1973). El artista presenta un potente chorro de materia roja que emana con fuerza de un gran agujero situado en lo alto de una pared, amontonándose en el suelo del espacio expositivo (fig. 15). Sin embargo, la materia utilizada por Kintera en nada se parece a la fluidez de la de Magyaroff. En su caso se trata de una pintura densa y pastosa que se ha congelado en su recorrido. La materia -exenta de la pared- exhibe su valor tridimensional, su cualidad de sustancia con volumen que ocupa un lugar en el espacio.

\section{Conclusiones}

Artistas contemporáneos como Peter Zimmermann, Rainer Splitt, Miguel Ángel Molina, Ian Davenport, Jorge Magyaroff o Kristof Kintera, cuestionan las convenciones de la tradición pictórica negando la representación, el pincel,

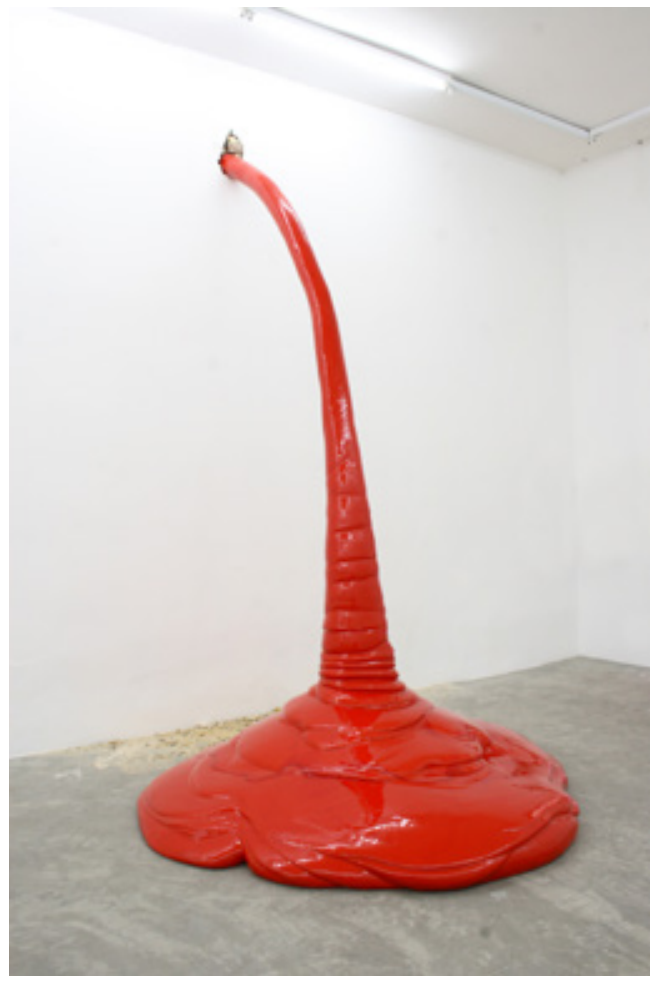

Fig. 15. Kintera, Kristof, Red is coming. Intervención en Galerie Schleicher+Lange, Paris, 2007

la destreza, el soporte-cuadro, la verticalidad del muro o la percepción frontal-paralela. En este proceso depurativo la pintura alcanza una esencia donde resuenan las aspiraciones de pureza y autorreferencialidad avaladas por la modernidad tardía. La pintura vertida en la pulcritud de los espacios expositivos, defiende una disciplina sin más normas que las dictadas por la naturaleza del propio medio.

Los charcos de pintura derramados por estos artistas recuperan el carácter transgresor de las Fallen Painting, pero la ironía de Linda Benglis parodiando el action painting se transforma, en este caso, en un gesto que reivindica la pintura como materia, la pintura, no como género o categoría, sino en su condición más elemental, la condición de sustancia untuosa con color que mancha.

Resulta paradójico que, siendo Benglis una artista feminista que denunció la dominante presencia masculina en el sistema del arte, sean mayoritariamente hombres los artistas que recu- 
Pisando charcos. La pintura sin soporte en el arte contemporáneo

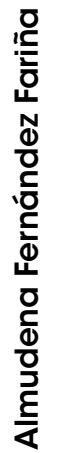

peran sus derrames de pintura. Los vertidos de color invadiendo el suelo de los espacios parecen recuperar el gesto heroico que Benglis parodiaba.

En definitiva, la vigencia de estas prácticas artísticas nos permite afirmar que la pintura, no sólo ha sido capaz de sobrevivir en plena era di- gital, sino que lo ha hecho mostrando su estado más puro. Sin el apoyo de otros elementos, sin artificios, sin cómplices, sin préstamos o intermediarios. La pintura en un estado irreductible, celebrando su existencia material. 


\section{NOTAS}

Esta corriente se enmarca en el contexto de la denominada "Pintura Expandida", dicho término fue apropiado del referencial ensayo de Rosalind Krauss, "La escultura en el campo expandido", publicado en 1979, donde la teórica estadounidense problematiza sobre las convenciones en las que asentaba la categoría de escultura, proponiendo su redefinición a partir de los evidentes cambios que experimenta desde final de los años sesenta. A pesar de que R. Krauss no profundiza en la revisión crítica de la categoría de pintura, su lógica de pensamiento fue determinante para asimilar aquellas prácticas pictóricas que, desde principios del siglo XX, habían planteado rupturas de las convenciones ligadas a aspectos instrumentales (el pincel), procesuales (manualidad), materiales (pigmentos y aglutinantes), espaciales (soportecuadro, cuadrangular/bidimensional) o perceptivos (visión frontal/estática). Las prácticas pictóricas analizadas en este artículo pueden calificarse como expansivas porque cuestionan todas las convenciones citadas, excepto las ligadas a la materialidad. Véase Rosalind $\mathrm{E}$. Krauss, "La escultura en el campo expandido", en La originalidad de la Vanguardia y otros mitos modernos (Madrid: Alianza Editorial, 1996), 289-303. Sobre pintura en el campo expandido véase Almudena Fernández Fariña, Lo que la pintura no es (Pontevedra: Edita Deputación de Pontevedra, 2010).

2 El sustrato material pictórico es el tradicionalmente compuesto por pigmentos, aglutinantes y disolventes.

${ }^{3}$ Clement Greenberg, crítico de arte norteamericano y gran narrador del pensamiento moderno, afirmaba: "Una obra modernista de arte debe procurar, en principio, evitar la dependencia de cualquier tipo de experiencia que no venga dada por la naturaleza esencial de su medio. Esto significa, entre otras cosas, renunciar a la ilusión y la explicitud. Las artes han de conseguir la concreción, la "pureza", actuando exclusivamente en función de sus yos separados e irreductibles". Clement Greenberg, "La nueva escultura", en Arte y cultura. Ensayos críticos (Barcelo- na: Gustavo Gili, 1979), 132. [entrecomillado en el original].

${ }^{4}$ Mímesis, según Norman Bryson, "describe la representación como un proceso de correspondencia perceptual por el que la imagen trata de igualarse, con distintos grados de éxito, a una realidad previa y plenamente construida". Norman Bryson, Visión y pintura. La lógica de la mirada (Madrid: Alianza Editorial, 1999), 54.

${ }^{5}$ La metáfora del espejo se refiere a la convención de la representación mimética a la que ha aspirado la producción pictórica desde las pinturas rupestres. En el libro X de La República Platón compara la imagen pintada con la imagen especular. Para Platón el reflejo especular explica el origen mimético de la pintura; cf. Platón, La República (Madrid: Editorial Aguilar, 1988), 469516.

${ }^{6}$ Leone Battista Alberti en su tratado De pictura (1435-1436) definía el cuadro como una ventana: "Lo primero, dibujo en la superficie a pintar un cuadrángulo de ángulos rectos, grande cuanto me place, que me sirve de ventana abierta desde la cual se ve la historia". La metáfora de la ventana se referirá a los sistemas de ordenamiento espacial y visual que han definido la práctica pictórica a partir del Renacimiento; cf. Leon Battista Alberti, Sobre la pintura (Valencia: Fernando TorresEditor, 1976), 105.

7 A lo largo de los siglos los pintores se sirvieron de diferentes recursos para que las imágenes ganaran fidelidad y fueran ilusiones, apariencias del mundo visible. Cada pintor intentaba aventajar a los que le habían precedido intentando alcanzar la utopía que Norman Bryson denomina "Copia Esencial", un simulacro, una réplica perfecta del mundo natural despojada de rasgos estilísticos, sin rastro del proceso productivo. Véase Bryson, Visión y pintura, 19.

${ }^{8}$ Véase Clement Greenberg, "La pintura moderna", en La pintura moderna y otros ensayos (Madrid: Ediciones Siruela, 2006), 112-113.

9 Javier Cabo Villaverde, "La visión dactilar: texturografía de la pintura contemporánea", Adaxe, nº (1991): 9.
${ }^{10}$ Michel Foucault, La pintura de Manet (Barcelona: Alpha Decay, 2005), 12.

${ }^{11}$ Véase Roman Gubern, La mirada opulenta. La exploración de la iconosfera contemporánea (Barcelona: Editorial Gustavo Gili, 1992), 74.

${ }^{12}$ Greenberg, "La pintura moderna", 113

${ }^{13}$ Michael Fried, Arte y objetualidad: Ensayos y reseñas (Madrid: Editorial A. Machado Libros, 2004), 258.

${ }^{14} \mathrm{Cf}$. Greenberg, "La pintura moderna", 112.

${ }^{15}$ Greenberg, "Abstracto y representacional", en Arte y Cultura, 129.

${ }^{16}$ Arthur Danto hace una analogía entre la pintura del expresionismo abstracto y el teatro. El equivalente coherente de esta pintura sería una producción teatral en la que la puesta en escena, en lugar de crear ilusión, mostraría los escenógrafos tirando de las cuerdas y moviendo los planos; cf. Arthur C. Danto, Después del fin del arte. El arte contemporáneo y el linde de la historia (Barcelona: Ediciones Paidós Ibérica, 1999), 98

${ }^{17} \mathrm{Cf}$. Harold Rosenberg, "Los pintores de acción norteamericanos", en La tradición de lo nuevo (Caracas: Ediciones Monte Ávila, 1969), 27-42.

${ }^{18}$ Aunque la relación cuerpo-soporte de Pollock y Frankenthaler merece un profundo análisis desde una perspectiva de género, es pertinente señalar cómo la postura corporal o los movimientos de ambos artistas están cargados de significación: Pollock, de pie, ocupa y domina el espacio, pisa el lienzo, lo rodea, salpica la pintura con gestos amplios e impulsivos; Frankenthaler pinta agachada o arrodillada junto al lienzo, con una postura controlada derrama la pintura con cuidado. Pollock y Frankenthaler representan dos formas de manejar el cuerpo en el proceso pictórico, dos formas profundamente ligadas a una actitud culturalmente impuesta y naturalmente aprendida.

${ }^{19}$ El látex, a diferencia de la pintura al óleo o el acrílico, tiene más densidad y al derramarse preserva el gesto de la artista. La flexibilidad del material permitía que, una vez secas las piezas, pudieran manipularse sin romperse. Benglis descubrió las posibilidades for- 
males del Látex líquido durante una visita en 1967 al estudio del artista Sol LeWitt, allí pudo ver una pequeña pieza que Eva Hesse había realizado como preparación para la escultura Schema (1967), Benglis quedó fascinada por la flexibilidad, brillo y textura del material. Véase Susan Richmond, Lynda Benglis. Beyond Process, (Londres; Nueva York: I.B. Tauris \& CO Ltd., 2015), 18.

${ }^{20}$ En la entrevista publicada en la revista digital Bomb, Lynda Benglis reconoce la influencia de Pollock y Frankenthaler: "Well, I became the material-much like Pollock or Frankenthaler described it, or any of the artists who were physically involved with the viscosity of their materials and how they went onto the surface. My surface was the floor, or the wall, or the room." Federica Bueti, "Lynda Benglis By Federica Bueti", Bomb, $n^{\circ}$ 138, Diciembre 15, 2016. https://bombmagazine.org/articles/lynda-benglis/.

${ }^{21}$ Véase Richmond, Lynda Benglis. Beyond Process, 21-23.

${ }^{22}$ Este rechazo lo relata Benglis en su entrevista publicada en la revista Bomb: "I did two very large floor paintings, and they were chosen for the Whitney Museum's Anti-Illusion show in 1969, but I had to pull out at the last minute because they didn't understand that the works had to be flat on the floor. Also, Richard Serra and Robert Ryman, who were also in that show, didn't want my color piece near them." Bueti, "Lynda Benglis By Federica Bueti".

${ }^{23} \mathrm{El}$ artículo "Fling, Dribble and Dip" firmado por David Bourdon, se publicó en la revista LIFE, el 27 de febrero de 1970. El trabajo de Benglis se presentaba junto al de Eva Hesse, Richard Serra y Richard Van Buren, artistas que, según el artículo, continuaban el legado de Jackson Pollock. El autor de las fotografías de Benglis, derramando pintura, es el fotografo Henry Groskinsky.

${ }^{24}$ La fotografía de Pollock pertenecía a la serie que Hans Namuth le realizó en su estudio de East Hampton en 1950.

${ }^{25}$ Las conexiones entre el trabajo de Benglis y el de Pollock rara vez fueron pasadas por alto en entrevistas, artículos o textos de catálogos. La comparación funcionó a favor de la artista, la reinterpretación del lenguaje de Pollock proporcionaba un marco crítico de referencia.

${ }^{26}$ Inicialmente la artista solicitó a Artforum que la imagen apareciera como poster central, pero la revista no lo permitió, ofreciéndole reproducir la imagen si se acompañaba de un artículo sobre su obra. Benglis rechazó la oferta de Artforum y decidió pagar por un es- pacio publicitario contratado a nombre de la Galería Paula Cooper.

${ }^{27}$ Las obras de Peter Zimmermann citadas pueden consultarse en la web oficial del artista. Véase http://peterzimmermann.com/de.

${ }^{28}$ Las obras de Rainer Splitt citadas pueden consultarse en la web oficial del artista. Véase http://www.rainersplitt. de.

${ }^{29}$ Las obras de Miguel Ángel Molina citadas pueden consultarse en la web oficial del artista. Véase http:// www.miguel-angel-molina.com.

${ }^{30}$ Miguel Ángel Molina, ed. "MAM. Miguel Ángel Molina", en Les autres oeuvres. La peinture et ses images (Montreuil: Éditions du Provisoire, 2010), 68.

${ }^{31}$ Las obras de lan Davenport citadas pueden consultarse en la web oficial del artista. Véase http:// www. iandavenportstudio.com.

${ }^{32}$ Las obras de Jorge Magyaroff citadas pueden consultarse en la web oficial del artista. Véase http:// www. jorgemagyaroff.com.

${ }^{33}$ Las obras de Kristof Kintera citadas pueden consultarse en la web oficial del artista. Véase http://kristofkintera.com. 


\section{REFERENCIAS}

Alberti, Leon Battista. 1976. Sobre la pintura. Valencia: Fernando Torres-editores.

Bell, Julian. 2001. ¿Qué es la pintura?: representación y arte moderno. Barcelona: Nueva Galaxia Gutenberg.

Bryson, Norman. 1999. Visión y pintura. La lógica de la mirada. Madrid: Alianza Editorial.

Bueti, Federica. 2016. "Lynda Benglis By Federica Bueti." Bomb magazine 138 (Diciembre 15). https://bombmagazine.org/articles/lyndabenglis/

Cabo Villaverde, Javier. 1991. "La visión dactilar: texturografía de la pintura contemporánea." Adaxe 7: 7-17. Santiago de Compostela: Universidad de Santiago de Compostela, Servicio de publicaciones.

Danto, Arthur. C. 1999. Después del fin del arte. El arte contemporáneo y el linde de la historia. Barcelona: Ediciones Paidós Ibérica.

Davenport, Ian. 2008. Ian Davenport: Poured lines. Londres: Wadington Galleries.

Davenport, lan. 2009. Puddle paintings / lan Davenport. Londres: Waddington Galleries.

Davenport, lan. 2011. lan Davenport: quick slow quick quick slow: paintings 2010-2011. Londres: Waddington Custot Galleries.

Fernández Fariña, Almudena. 2010. Lo que la pintura no es. Colección Arte \& Estética. Pontevedra: Deputación de Pontevedra.

Godfrey, Tony. 2010. La pintura hoy. Londres: Phaidon.

González García, Angel. 2007. Pintar sin tener ni idea; $y$ otros ensayos sobre arte. Madrid: Lampreave y Millán.

Foucault, Michel. 2005. La pintura de Manet. Barcelona: Alpha Decay.

Fried, Michael. 2004. Arte y objetualidad. Ensayos y reseñas. Madrid: A. Machado Libros.

Greenberg, Clement. 2002. Arte y cultura. Barcelona: Paidós Ibérica.
Greenberg, Clement. 2006. La pintura moderna y otros ensayos. Madrid: Siruela.

Gubern, Roman. 1992. La mirada opulenta. La exploración de la iconosfera contemporánea. Barcelona: Editorial Gustavo Gili.

Kintera, Kristof, Karel Srp, y Mariana Serranova. 2013. Kristof Kintera. Praga: Nakladatelstvi Arbor Vitae.

Krauss, Rosalind E. 1996. "La escultura en el campo expandido." En La originalidad de la Vanguardia y otros mitos modernos, 289-303. Madrid: Alianza Editorial.

Molina, Miguel Angel. 2010. Las otras obras. Montreuil: Éditions du Provisoire.

Mont, Miquel, y Gloria Picazo. 2008. Afinidades electivas. Lleida: Centre d'Art la Panera.

Platón. 1998. La República. Madrid: Aguilar.

Richmond, Susan. 2015. Lynda Benglis. Beyond process. Londres; New York: I.B. Tauris \& Co Ltd.

Rosenberg, Harold. 1969. "Los pintores de acción norteamericanos." En La tradición de lo nuevo, 27-42. Caracas: Ediciones Monte Ávila.

Sabino, Isabel. 1999. A pintura Despois da Pintura. Lisboa: Biblioteca d'Artes, Universidade de Lisboa.

Sobrino Manzanares, María Luisa, y Almudena Fernández Fariña, eds. 2015. Arte + Pintura. Santiago de Compostela: Consello da Cultura Galega.

Splitt, Rainer. 2014. Pourings. Otterndorf: Museum Gegenstandsfreier Kunst.

Stoichita, Víctor I. 2000. La invención del cuadro. Arte, artífices y artificios en los orígenes de la pintura europea. Barcelona: Ediciones del Serbal.

Zimmermann, Peter. 2013. Peter Zimmermann. Paris: Galerie Perrotin.

Zimmermann, Peter. 2016. Capas de gelatina. Málaga: Centro de Arte Contemporáneo de Málaga. 